\title{
Uji Efektivitas Ekstrak Daun Bunga Pukul Empat (Mirabilis jalapaL.)Sebagai Obat Luka Bakar pada Kelinci Putih Jantan
}

\author{
Fathnur Sani $\mathrm{K}^{1}$, Gatot Prasetya ${ }^{2}$, Nurfijrin Ramadhani ${ }^{3}$, Nurwani Purnama Aji ${ }^{4}$, \\ Agung Giri Samudra ${ }^{5}$ \\ ${ }^{1}$ Program Studi Farmasi Fakultas Kedokteran dan Ilmu Kesehatan Universitas Jambi \\ ${ }^{2,4}$ Sekolah Tinggi Kesehatan Al-Fatah Bengkulu \\ ${ }^{3,5}$ Program Studi Farmasi Universitas Bengkulu \\ ${ }^{1}$ Email:fathnursanik@unja.ac.id
}

\begin{abstract}
ABSTRAK
Daun bunga pukul empat (Mirabilis jalapa L.) merupakan salah satu tumbuhan yang berpotensi sebagai pengobatan untuk luka bakar karena mengandung senyawa alkaloid, flavonoid, saponin, triterpenoid dan tanin. Tujuan penelitian ini untuk mengetahui efektifitas daun bunga pukul empat dalam mengatasi luka bakar.Metode pengujian Efektivitas ekstrak daun bunga pukul empat sebagai luka bakar diuji menggunakan metode induksi luka bakar. Hewan Uji terdiri dari 5 ekor kelinci yang dibagi menjadi 5 kelompok yaitu kelompok kontrol negatif (vaselin flava), kontrol positif (Bioplasenton), dan kelompok perlakuan ekstrak etanol daun bunga pukul empat Perlakuan I (5\% b/b), Perlakuan II (7,5\%b/b) dan Perlakuan III (10\%b/b). Pengukuran diameter luka bakar dilakukan dari hari ke-1 hingga hari ke-19 diukur setiap 3 hari.Data diperoleh menggunakan analisis uji statistik two-way anova dilanjutkan dengan uji duncandengan tingkat kepercayaan 95\%.Hasil penelitian menunjukkan bahwa ekstrak daun bunga pukul empat mempunyai efek penyembuhan luka bakar. Dimana berdasarkan hasil uji statistik terdapat perbedaan yang bermakna untuk tiap kelompok perlakuan.Konsentrasi terbaik adalah perlakuan III konsentrasi $10 \%$ dengan persentase kesembuhan $85,08 \%$ dengan nilai signifikansi berbeda nyata $(\mathrm{p}<0,05)$. Kemudian diikuti dengan konsentrasi 7,5\% b/bdan 5\%b/b.
\end{abstract}

Kata Kunci : Mirabillis jalapa,

Luka Bakar, Kelinci, Anova Dua Arah

\section{PENDAHULUAN}

Penggunaan

tanaman

berkhasiat obat di Indonesia dilakukan sebagian besar masih berdasarkan pengalaman dan keterampilan yang diwariskan secara turun temurun sebagai upaya menanggulangu masalah kesehatan.Pengobatan dengan terapi herbal mempunyai keunggulan dan kelebihan dibandingkan dengan pengobatan menggunakan kimia sintetik. Adapun keunggulan tersebut adalah dapat diperoleh tanpa resep dokter, halal, daya keterserapannya $90 \%$, dapat di racik sendiri, harga murah dan dapat juga ditanam sendiri(Elshabrina, 2018).

Luka bakar adalah bentuk kerusakan jaringan yang disebabkan kontak dengan sumber panas lendir, saluran pernapasan, dan saluran cerna. Gejalanya berupa sakit, bengkak, 
merah, melepuh karena permeabiltas pembuluh darah meningkat(Hasyim et al., 2012). Kejadian luka bakar masih menjadi permasalahn besar di masyarakat. Dimana luka bakar yang parah dapat berdampak pada gangguan permanen pada penampilan dan fungsi organ(Menkes RI, 2019).

Penanganan luka bakar dilakukan dengan memberikan terapi lokal yang bertujuan untuk mendapat kesembuhan yang cepat. Tanaman bunga pukul empat (Mirabillis jalapa) mengandung senyawa metabolit sekunder yaitu alkaloid, flavonoid, saponin, dan tannin. Dimana berdasarkan hasil penelitian yang dilakukan oleh Sani dkk (2015) mendapatkan bahwa ekstrak daun bunga pukul empat memiliki efektivitas terhadap bakteri gram positif dan negatif (Sani et al., 2015). Bakteri sangat mudah masuk pada bagian tubuh yang mengalami luka terkelupas hal ini akan menimbulkan infeksi pada luka (Kwei, 2015).

Berdasarkan permasalahan
diatas maka peneliti tertarik
melakukan penelitian yang berjudul UjiEfektivitas Ekstrak

DaunBungaPukulEmpat (Mirabilis jalapa) sebagai Obat Luka Bakar.

\section{METODE}

Alat

Alat-alat yang digunakan dalam penelitian ini meliputi : alat gelas laboratorium, neraca analitis, hotplate, termometer raksa, lempeng logam 500 berdiameter $2,4 \mathrm{~cm}$, pisau cukur, stopwatch, penggaris, gunting, spidol, tabung reaksi, rak tabung reaksi, rotary evaporator, botol coklat.

\section{Bahan}

Bahan yang akan digunakan dalam penelitian ini melipiti ; daun bunga pukul empat (Mirabilis jalapaL.)konsentrasi $5 \%$ b/b, 7,5\% b/b, dan 10\%b/b, alkohol, Hcl 1\%, reagen mayer, reagen wagner, dragendorf, $\mathrm{Mg}, \mathrm{FeCl}_{3}$, kloroform, asam sulfat pekat, asam asetat glasial, $\mathrm{Mg}, \mathrm{HCl} \mathrm{p}$, etanol 2\%, aquadest.

\section{Hewan Percobaan}

Dalam pengujian ini hewan coba yang digunakan adalah kelinci jantan (Oryctolagus cuniculus) galur local yang sehat, dengan berat badan 1,0 $1,9 \mathrm{~kg}$.

\section{Verifikasi}

Verifikasi

taksonomi tumbuhan dilakukan di Laboratorium Biologi Fakultas Matematika dan Ilmu Pengetahuan Alam Universitas Bengkulu.

\section{Prosedur Kerja Penelitian}




\section{Penyiapan Ekstrak Daun Bunga Pukul Empat}

Pembuatan ekstrak daun

bungapukulempatdiawalidengan

pengambilan sampel, pencucian, perajangan, dikeringkan yaitu dengan cara diangin-anginkan, dan penimbanganbahan-bahan yang diperlukan. Proses maserasi daun bunga pukul 4 ditimbang sebanyak 500 gram dimasukkan kedalam botol berwarna gelap dan di tambahkan pelarut etanol $96 \%$ hingga ekstrak terendam dan diamkan selama 3-5 hari kemudian lakukan pengulangan hingga larutan jernih atau jenuh, lalu disaring dengan kain flanel dan hasil maserat diuapkan dengan rotary evaporator.

\section{Skrining Fitokimia}

Skrining fitokimia pada penelitian ini adalah alkaloid, triterpenoid, flavonoid, saponin, steroid dan tannin.

\section{Uji Efektivitas Penyembuh Luka}

Sebanyak 5 ekor hewan uji diadaptasi selama dua minggu. Masing-masing kelinci ditimbang dan diberi tanda pembeda pada telinga kelinci. Setelah itu masing-masing punggung kelinci dibuat lima area perlakuan dengan lebar $3 \times 3 \mathrm{~cm}$ dan jarak antar area $2 \mathrm{~cm}$. Kemudian dilakukan pencukuran rambut kelinci pada lima area tersebut, menggunakan pisau cukur. Cukur bulu sesuai pola yang telah dibuat sekitar punggung bagian tengah kelinci sebanyak 5 petak, 3 kanan dan 2 kiri lalu bersihkan menggunakan kapas dengan alkohol diamkan selama semalam.

Masing-masing bagian yang sudah ditandai dan dicukur kemudian ditempel dengan logam yang telah dipanaskan dengan hotplate (suhu $80^{\circ} \mathrm{C}$ ) selama 5 menit dengan diameter 2,4 cm (koin Rp.500) dan di tempelkan pada kulit punggung kelinci selama 10 detik atau hingga kulit terangkat dan terkelupas.

Adapun variasi perlakuan pada hewan percobaanyaitu :

$\mathrm{K}-=$ Vaselin flavum (kontrol negatif) $\mathrm{K}+=$ Bioplacenton (kontrol positif)

P1 = Ekstrak daun bunga pukul empat (Mirabillis jalapa) $5 \%$ tambahkan Vaseline flavum ad $10 \mathrm{gr}$

P2 = Ekstrak daun bunga pukul empat (Mirabillis jalapa) $\quad 7,5 \%$ tambahkan Vaseline flavum ad $10 \mathrm{gr}$

P3 = Ekstrak daun bunga pukul empat (Mirabillis jalapa) $10 \%$ tambahkan Vaseline flavum ad $10 \mathrm{gr}$ 
Pengujian efektivitas penyembuh luka dari daun bunga pukul empat (Mirabilis jalapa L.) dilakukan dengan cara mengoleskan sebanyak 0,1 gram dua kali sehari yaitu pada pagi dan sore pada tiap daerah luka. Pengukuran diameter luka bakar menggunakan jangka sorong dilakukan dengan metode Morton yaitu pengukuran interval 3 hari sekali (hari ke 1, 4, 7, 10, 13, 16, 19) sampai maksimal hari ke 19.Luka diamati secara visual dengan melihat kondisi luka mulai dari luka mengalami inflamasi sampai luka kering dan menutup.Luka bakar yang terbentuk diukur menggunakan penggaris kemudian dihitung diamer luka bakar dengan rumus(Alinda et al., 2018):

$$
d x=\frac{d 1+d 2+d 3+d 4}{4}
$$

Keterangan :

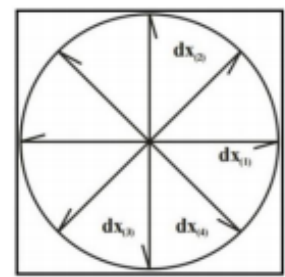

$\mathrm{dx}=$ Diameter luka hari ke- $\mathrm{x}$

$\mathrm{d}_{1}=$ Diameter 1

$\mathrm{d} 2$ = Diameter 2

d3 = Diameter 3

$\mathrm{d}_{4}=$ Diameter 4

Gambar 1. Cara Mengukur

Diameter Luka Bakar

Hasil rata-rata diameter diperoleh merupakan hasil diameter luka dengan satuan sentimeter $(\mathrm{cm})$, maka selanjutnya dapat dibuat menjadi satuan persen (\%) dengan rumus :

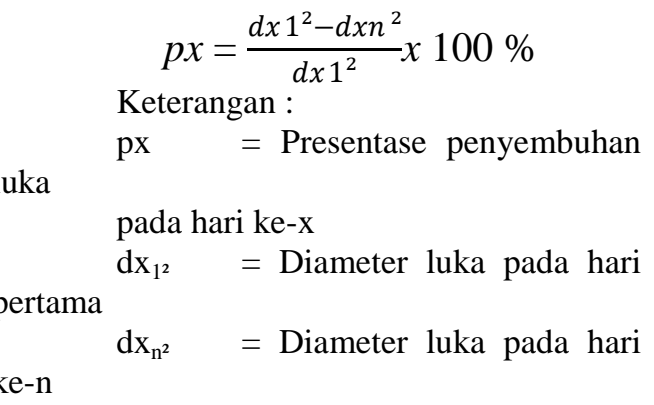

\section{Analisis Data}

Analisis hasil penelitian pada penyembuhan luka dilakukan denganmengolah data secara statistik dengan Uji ANOVA dua arah dilanjutkan dengan uji Duncan dengan taraf kepercayaan $95 \%$.

\section{HASIL DAN PEMBAHASAN}

\section{Verifikasi Tanaman Bunga Pukul}

\section{Empat (Mirabillis jalapa L.)}

Berdasarkan surat keterangan nomor: 003/H.30.7/PP/2019 Hasil verifikasi taksonomi tumbuhan yang dilakukan Laboratorium Biologi Fakultas Matematika dan Ilmu Pengetahuan Alam Universitas Bengkulu.

\section{Ekstraksi Daun Bunga Pukul}

\section{Empat (Mirabillis jalapa L.)}

Simplisia Daun Bunga Pukul Empat dilakukan sortasi kemudian di kering anginkan tanpa terkena sinar matahari langsung. Tujuan dilakukannya 
pengeringan adalah untuk membantu mengurangi kadar air sehingga dapat mencegah terjadinya pembusukan dan tumbuhnya mikroorganisme. Parameter yang menunjukkan daun telah kering secara sempurna yaitu daun dapat diremahkan(Luliana et al., 2016). Adapun hasil rendemen ekstrak yang di dapat dari proses ekstraksi adalah 7,57\%. Nuralifah et al. (2018) mengatakan bahwa tujuan dari melakukan penetapan rendemen simplisia adalah untuk mengetahui perkiraan jumlah simplisia yang diperlukan dalam pembuatan ekstrak kental(Nuralifah et al., 2018).

\section{Skrining Fitokimia}

Berdasarkan skrining fitokimia ekstrak daun bunga pukul empat (Mirabilis jalapa L.) didapatkan hasil positif pada beberapa senyawa metabolit skunder seperti yang ditunjukkan pada tabel dibawah ini.

Tabel 1. Hasil Skrining Fitokimia

\begin{tabular}{|c|c|c|c|c|}
\hline $\begin{array}{l}\mathbf{N} \\
\mathbf{0}\end{array}$ & $\begin{array}{c}\text { Uji } \\
\text { Fitoki } \\
\text { mia } \\
\end{array}$ & $\begin{array}{c}\text { Perea } \\
\text { ksi }\end{array}$ & $\begin{array}{c}\text { Perub } \\
\text { ahan } \\
\text { Warna }\end{array}$ & $\begin{array}{c}\text { Ketera } \\
\text { ngan }\end{array}$ \\
\hline 1 & $\begin{array}{l}\text { Alkaloi } \\
\text { d }\end{array}$ & $\begin{array}{l}\mathrm{Hcl} \\
1 \%+ \\
\text { mayer }\end{array}$ & $\begin{array}{l}\text { Endapa } \\
\mathrm{n} \\
\text { kuning } \\
\text { (mayer } \\
\text { ) }\end{array}$ & + \\
\hline 2 & $\begin{array}{l}\text { Triterp } \\
\text { enoid }\end{array}$ & $\begin{array}{l}\mathrm{CH}_{3} \mathrm{C} \\
\mathrm{OOH} \\
+ \\
\mathrm{H}_{2} \mathrm{SO}_{4} \\
\mathrm{p}\end{array}$ & Merah & + \\
\hline 3 & $\begin{array}{l}\text { Flavon } \\
\text { oid }\end{array}$ & $\begin{array}{l}\mathrm{Mg}+ \\
\mathrm{Hcl} \mathrm{p}\end{array}$ & Kuning & + \\
\hline
\end{tabular}

\begin{tabular}{|c|c|c|c|c|}
\hline 4 & $\begin{array}{l}\text { Saponi } \\
\mathrm{n}\end{array}$ & $\begin{array}{l}\text { Etanol } \\
2 \%+ \\
\text { aq.dest }\end{array}$ & $\begin{array}{l}\text { Tinggi } \\
\text { busa > } \\
2 \mathrm{~cm}\end{array}$ & + \\
\hline 5 & Steroid & $\begin{array}{l}\text { Etanol } \\
70 \%+ \\
\text { klorof } \\
\text { orm + } \\
\mathrm{H}_{2} \mathrm{SO}_{4}\end{array}$ & $\begin{array}{l}\text { Cincin } \\
\text { merah }\end{array}$ & - \\
\hline 6 & Tanin & $\begin{array}{l}\text { Etanol } \\
70 \%+ \\
\mathrm{FeCl}_{3}\end{array}$ & $\begin{array}{l}\text { Biru, } \\
\text { biru- } \\
\text { hitam, } \\
\text { biru- } \\
\text { hijau } \\
\text { dan } \\
\text { endapa } \\
\text { n }\end{array}$ & + \\
\hline
\end{tabular}

Keterangan: $(+)=$ Mengandung metabolit sekunder

$(-)$ = Tidak mengandung metabolit sekunder

Pengujian skrining fitokimia dilakukan secara kualitatif. Hasil pengujian menunjukkan bahwa ekstrak daun bunga pukul empat (Mirabilis jalapa L.) mengandung senyawa alkaloid, triterpenoid, flavonoid, saponin dan tannin. Hal ini sejalan dengan penelitian yang dilakukan oleh Oktaviana(2018) dan Sani et al.(2015).

\section{Efektivitas Penyembuhan Luka}

\section{Bakar Ekstrak Daun Bunga Pukul} Empat (Mirabillis jalapa L.)

Hasil penelitian uji efektivitas ekstrak etanol daun bunga pukul empat (Mirabillis jalapaL.) menunjukkan adanya efek penyembuhan luka bakar pada hewan uji kelinci. Dimana hasil pengukuran diameter adalah sebagai berikut:Tabel 
1. Hasil Pengukuran diameter luka setelah perlakuan

\begin{tabular}{|c|c|c|c|c|c|c|c|}
\hline Kelo & \multicolumn{7}{|c|}{ Hari ke- (cm) } \\
\cline { 2 - 9 } $\begin{array}{c}\text { mpok } \\
\text { Perla } \\
\text { kuan }\end{array}$ & $\mathbf{1}$ & $\mathbf{4}$ & $\mathbf{7}$ & $\mathbf{1 0}$ & $\mathbf{1 3}$ & $\mathbf{1 6}$ & $\mathbf{1 9}$ \\
\hline K (+) & 2, & 2, & 1, & 1, & 1, & 1, & 0, \\
& 30 & 11 & 89 & 66 & 36 & 02 & 62 \\
\hline K (-) & 2, & 2, & 2, & 2, & 2, & 1, & 1, \\
& 23 & 24 & 21 & 13 & 01 & 81 & 46 \\
\hline P1 & 2, & 2, & 2, & 1, & 1, & 1, & 1, \\
& 13 & 08 & 08 & 88 & 71 & 55 & 27 \\
\hline P2 & 2, & 2, & 1, & 1, & 1, & 1, & 1, \\
& 22 & 16 & 99 & 83 & 61 & 38 & 05 \\
\hline P3 & 2, & 2, & 1, & 1, & 1, & 1, & 0, \\
& 18 & 06 & 87 & 65 & 47 & 17 & 84 \\
\hline
\end{tabular}

Hasil pengukuran diameter

luka pada Tabel 1 menunjukkan bahwa semakin tinggi konsentrasi perlakuan ekstrak daun bunga pukul empat (Mirabillis jalapa L) semakin baik tingkat kesembuhan yang diberikan. Hasil perhitungan persentase tingkat kesembuhan luka bakar pada kelinci selama perlakuan dapat dilihat pada Tabel 2.

Tabel 2. Persentase rata-rata kesembuhan luka bakar kelinci setelah perlakuan

\begin{tabular}{|c|c|c|c|c|c|c|}
\hline Kelo & \multicolumn{7}{|c|}{ Hari ke- (\%) } \\
\cline { 2 - 7 } $\begin{array}{c}\text { mpok } \\
\text { Perla } \\
\text { kuan }\end{array}$ & $\mathbf{4}$ & $\mathbf{7}$ & $\mathbf{1 0}$ & $\mathbf{1 3}$ & $\mathbf{1 6}$ & $\mathbf{1 9}$ \\
\hline K(+) & 15, & 33, & 48, & 65, & 80, & 92, \\
& 81 & 13 & 45 & 44 & 42 & 76 \\
\hline K (-) & & 2,7 & 9,2 & 18, & 34, & 57, \\
& 0 & 5 & 6 & 8 & 63 & 21 \\
\hline P1 & 4,6 & 12, & 21, & 35, & 46, & 64, \\
& 5 & 74 & 73 & 62 & 8 & 56 \\
\hline P2 & 6,2 & 20, & 32, & 47, & 61, & 77, \\
& 1 & 05 & 42 & 4 & 64 & 84 \\
\hline P3 & 10, & 26, & 42, & 54, & 70, & 85, \\
\hline
\end{tabular}

\begin{tabular}{|l|c|c|c|c|c|c|}
\hline & 3 & 47 & 8 & 45 & 91 & 08 \\
\hline Hasil & \multicolumn{4}{|c|}{ perhitungan } & \multicolumn{4}{|c|}{ persentase }
\end{tabular}

kesembuhan menunjukkan adanya perubahan nilai yang signifikan setiap pengukuran.Gambaran hasil peningkatan efektivitas penyembuhan dapat dilihat pada Gambar 2.

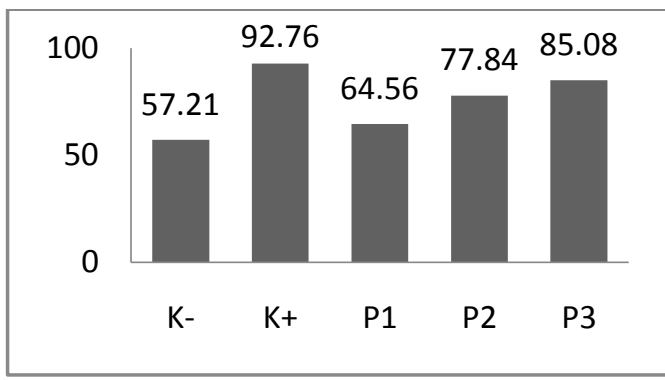

Gambar 2.Persentase Kesembuhan Luka Bakar Kelinci Setelah Pemberian Perlakuan dengan Ektrak Daun Bunga Pukul Empat (Mirabillis jalapa L.)

Perubahan nilai persentase yang signifikan selama pengukuran juga terlihat dari hasil uji statistik anova dua arah yang memperlihatkan adanya perbedaan yang signifikan $(\mathrm{p}<0,05)$ setiap pengukuran diameter luka. Secara statistik perlakuan terbaik adalah perlakuan 3 dengan konsentrasi ekstrak yang diberikan adalah $10 \%$. Dimana hasil uji lanjutan menunjukkan bahawa perlakuan 3 memiliki efek yang sama dengan kontrol positif kemudian diikuti dengan perlakuan 2 dan perlakuan 1.

Percepatan kesembuhan luka bakar yang diberikan oleh ekstrak 
daun bunga pukul empat (Mirabillis jalapa L.) didapatkan karena adanya kandungan senyawa metabolit sekunder didalamnya. Dimana data ini terdeteksi secara kualitatif melalui proses skrining fitokimia. Adapun hasil yang didapat dari skrining fitokimia menyatakan bahwa ekstrak daun bunga pukul empat (Mirabillis jalapaL.) mengandung senyawa alkaloid, triterpenoid, flavonoid, saponin dan tannin.Hal ini sejalan dengan penelitian yang dilakukan oleh Sani dkk. (2015) dan Oktaviana (2018)(Oktaviana, 2018; Sani et al., 2015).

Metabolit sekunder yang terdapat pada ekstrak daun bunga pukul empat (Mirabillis jalapaL.) seluruhnya memiliki peranan yang kuat dalam penyembuhan luka bakar pada kelinci. Alkaloid memiliki peranan dalam proses peningkatan proliferasi seluler pada lokasi luka yang disebabkan karena sintesis kolagen yang mengendap. sehingga alkaloid dapat berkontribusi dalam penyembuhan luka dengan cara regenerasi dermal dan epidermal yang akan memberikan efek positif bagi tahap proliferasi seluler, pembentukan jaringan granular, epitelisasiserta berperan dalam mengurangi inflamasi yang terjadi saat luka(Safani et al., 2019; Yassine et al., 2020).

Flavonoid pada ekstrak daun bunga pukul empat memiliki peran yang cukup besar dalam proses penyembuhan luka. Dimana flavonoid mampu berperan sebagai antibakteri, antioksidan serta antiinflamasi(Antunes-Ricardo et al., 2015; Bapat \& Mhapsekar, 2014). Saponin berperan dalam meningkatkan kemampuan reseptor TGF- $\beta$ fibroblast berikatan dengan TGF- $\beta$.TGF- $\beta$ merupakan factor pertumbuhan yang diperlukan fibroblast dalam mensintesis kolagen untuk percepatan kesembuhan luka.Tannin berperan sebagai antibakteri dan peningkat epitelisasi. Selain itu tannin juga diduga berperan dalam pengaturan traksripsi dan translasi Vascular Endothelial growth factor (VEGF)(Putrianirma et al., 2019). VEGF berperan secara parakrin tidak hanya pada sel endotel vascular kulit tetapi juga keratinosit dan sel imun yang memperlihatkan efek repitelisasi pada saat yang sama juga berperan dalam pemulihan angiogenesis serta perfusi oksigen(Pastar et al., 2014).

KESIMPULAN 
Hasil pengujian efek luka bakar dari ekstrak daun bunga pukul empat menunjukkan bahwa ekstrak daun bunga pukul empat (Mirabillis jalapa) memiliki efek sebagai obat luka bakar. Dimana secara statistik pengujian anova 2 arah didapatkan bahwa ada perbedaan yang bermakna antar kelompok perlakuan $(\mathrm{P}<0,05)$. Konsentrasi terbaik dalam penyembuhan luka bakar adalah konsentrasi $10 \%$ dengan persentase kesembuhan 92,08\%. Kemudian diikuti dengan konsentrasi 7,5\% dan $5 \%$.

\section{DAFTAR PUSTAKA}

Alinda, A., Syed Norris, H., Marlia, P., Siti Hamisah, T., Cotet, G. B., Balgiu, B. A., Zaleschi (Negrea), V. - C., Matusevych, T., Abu Ahmad, I., Teknologi, U., Bandar, M., Abdul, TunAli, S., Rose, Pahang, R., Pendidikan, F., National Education Association (NEA), Information Management Department, HASSAN, C. N. B., Luthfi, A., ... Othman, A. (2018). Efektivitas Salep Ekstrak Etanol $70 \%$ Daun Pandan Wangi Terhadap Penyembuhan Luka Bakar Pada Mencit Putih Jantan.Fitofarmaka Jurnal Ilmiah Farmasi, 8(1), 32-42. https://doi.org/10.1051/mateccon f/201712107005

Antunes-Ricardo, M., GutierrezUribe, J., \& Serna-Saldivar, S. (2015). Anti-inflammatory Glycosylated Flavonoids as Therapeutic Agents for Treatment of Diabetes-Impaired

\section{Wounds. Current Topics in Medicinal Chemistry. https://doi.org/10.2174/15680266 15666150619141702}

Bapat, U. C., \& Mhapsekar, D. R. (2014). Phytochemical investigations and antimicrobial and anticancer activities of Homonoia riparia lour. International Journal of Pharmacy and Pharmaceutical Sciences, 6(11), 237-243.

\section{Elshabrina. (2018). 33 DAUN DAHSYAT TUMPAS BERBAGAI MACAM PENYAKIT. BUKU.}

Hasyim, N., Pare, K. L., Farmasi, F., Hasanuddin, U., \& Timur, U. I. (2012). Formulasi dan Uji Efektifitas ekstrak Daun Cocor Bebek pada Kelinci. Medical Journal of Hasanuddin University.

Kwei J, Halstead FD, Dretzke J, Oppenheim BA, Moiemen NS. 2015. Protocol for a systematic review of quantitative burn wound microbiology in the management of burns patients. $4(1): 150$

Luliana, S., Purwanti, N. U., \& Manihuruk, K. N. (2016). Pengaruh Cara Pengeringan Simplisia Daun Senggani (Melastoma malabathricum L.) Terhadap Aktivitas Antioksidan Menggunakan Metode DPPH (2,2-difenil-1-pikrilhidrazil).

Pharmaceutical Sciences and Research.https://doi.org/10.7454/ psr.v3i3.3291

Menkes RI. (2019). Keputusan Menteri Kesehatan Republik Indonesia Nomor Hk.01.07/Menkes/555/2019

Tentang Pedoman Nasional 
Pelayanan Kedokteran Tata Laksana Luka Bakar. In Pedoman Nasional Pelayanan Kedokteran Tata Laksana Luka Bakar (Vol. 4, Issue 1). https://doi.org/.1037//0033-

2909.I26.1.78

Nuralifah, N., Jabbar, A., Parawansah, P., \& Iko, R. A. (2018). Uji Toksisitas Akut Ekstrak Etanol Daun Notika (Archboldiodendron calosercium (Kobuski)) Terhadap Larva Artemia salina Leach dengan Menggunakan Metode Brine Shrimp Lethality Test (BSLT). Pharmauho: Jurnal Farmasi, Sains, Dan Kesehatan, 4(1), 1-5. https://doi.org/10.33772/pharmau ho.v4i1.4618

Oktaviana, O. (2018). ( Mirabilis jalapa ) Sebagai Ovisida Nyamuk Aedes Aegypti Universitas Islam Negeri Raden Intan Lampung 1439 H $/ 2018$ Efektivitas Ekstrak Daun Bunga Pukul Empat ( Mirabilis jalapa ) Sebagai Ovisida Nyamuk Aedes aegypti. $1-125$.

Pastar, I., Stojadinovic, O., Yin, N. C., Ramirez, H., Nusbaum, A. G., Sawaya, A., Patel, S. B., Khalid, L., Isseroff, R. R., \& TomicCanic, M. (2014). Epithelialization in Wound Healing: A Comprehensive Review. Advances in Wound Care, 3(7), 445-464. https://doi.org/10.1089/wound.20 13.0473

Putrianirma, R., Triakoso, N., Yunita,
M. N., Yudaniayanti, I. S., Hamid, I. S., \& Fikri, F. (2019). Efektivitas Ekstrak Daun Afrika (Vernonia amygdalina) Secara Topikal Untuk Reepitelisasi Penyembuhan Luka Insisi Pada Tikus Putih (Rattus novergicus). Jurnal Medik Veteriner, 2(1), 30. https://doi.org/10.20473/jmv.vol2 .iss1.2019.30-35

Safani, E. E., Kunharjito, W. A. C., Lestari, A., \& Purnama, E. R. (2019). Potensi Ekstrak Daun Bandotan (Ageratum conyzoides L.) Sebagai Spray Untuk Pemulihan Luka Mencit Diabetik Yang Terinfeksi Staphylococcus aureus. Biotropic: The Journal of Tropical Biology, 3(1), 68-78. https://doi.org/10.29080/biotropic .2019.3.1.68-78

Sani, F., Dominica, D., \& Indika, H. (2015). Uji Efektivitas Antibakteri Ekstrak Etanol Daun Kembang Pukul Empat ( Mirabilis jalapa L .) Terhadap Bakteri Staphylococcus aureus Dan Escherichia coli ( Antibacterial Activity of Ethanol Extract of Kembang Pukul Empat ( Mirabilis Jalapa L .) Against Bact. 6-7.

Yassine, K. A., Houari, H., Mokhtar, B., Karim, A., Hadjer, S., \& Imane, B. (2020). A topical ointment formulation containing leaves' powder of Lawsonia inermis accelerate excision wound healing in Wistar rats. Veterinary World, July. https://doi.org/10.14202/vetworld .2020.1280-1287 

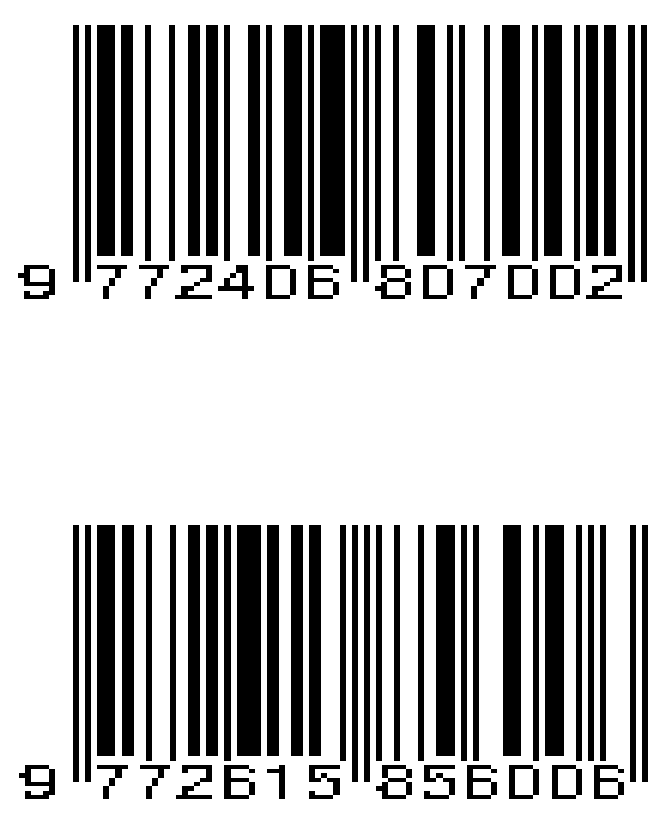